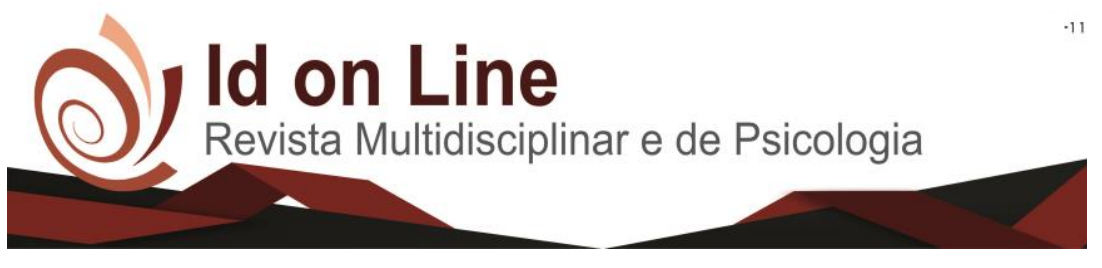

DOI: 10.14295/idonline.v13i46.2013

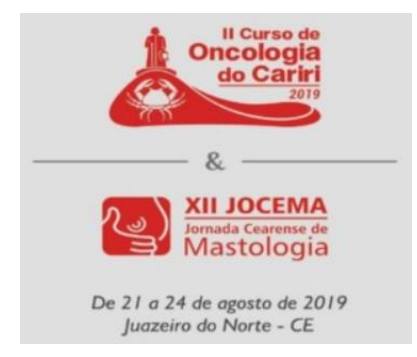

Resumo

\title{
MEDULOBLASTOMA ANAPLÁSICO: UM RELATO DE CASO
}

\author{
Maria Isabel Rolim Almino ${ }^{l}$; Ana Cristina Ferreira de Lucena ${ }^{l}$; Diego Oliveira dos Santos ${ }^{l}$; Alexia Maria \\ França Aragão ${ }^{2}$; João Marcos Ferreira de Lima Silva ${ }^{3}$; Maria Joatônia Caldas Rolim de Oliveira ${ }^{4}$
}

Introdução: As neoplasias cerebrais são os tumores sólidos mais comuns em crianças, correspondendo a $20 \%$ do total nessa população. Na maioria dos casos, o diagnóstico é tardio, com doença avançada e de pior prognóstico, representando a causa mais comum de morte dentre os carcinomas que ocorrem na infância. Múltiplos fatores podem contribuir para o atraso no diagnóstico, como a variabilidade clínica conforme a sua localização, o tipo histopatológico, a taxa de crescimento tumoral e a idade da criança. Objetivo: O objetivo desse trabalho consiste em refletir sobre as nuances da prática clínica, enfatizando os aspectos que podem promover o diagnóstico precoce de tumores do sistema nervoso central (SNC) na população pediátrica. Caso: K.G.O.S., sexo masculino, oito anos de idade, com cefaleia, náuseas e vômitos em jato, inicialmente medicado pelos pais com sintomáticos. Sem melhora, procuraram à Unidade Básica de Saúde, na qual também não houve resolução do problema. Assim, com a persistência do quadro, foi atendido, por duas vezes, em emergência pediátrica, onde foi administrado antiemético, sem qualquer investigação ou encaminhamento. A continuidade do quadro clínico, cerca de trinta dias após seu início, levou o genitor e a criança ao ambulatório de pediatria do Posto de Assistência Médica - PAM Crato, em abril de 2017. Nesse atendimento, diante de sinais e sintomas sugestivos de aumento de pressão intracraniana (PIC), foi aventada a hipótese de tumor cerebral, solicitado ressonância magnética do crânio, que confirmou massa craniana em fossa posterior, bem como hidrocefalia. O paciente foi então encaminhado ao centro de referência em oncologia pediátrica, em Fortaleza, no qual realizou procedimentos diagnósticos e terapêuticos. O exame histopatológico definiu tratar-se de meduloblastoma anaplásico, com características prognósticas desfavoráveis, ocorrendo o óbito da criança no vigésimo sétimo dia de pós-operatório. Conclusão: Conclui-se que a relevância desse caso consiste em promover uma reflexão tanto sobre fatores que dificultam o diagnóstico de tumor cerebral, quanto da importância em reconhecer os sinais de hipertensão intracraniana (HIC) e sua correlação com tumores de SNC. Ademais, considera-se que, apesar do desfecho negativo, o diagnóstico correto foi imprescindível para o encaminhamento ao serviço de referência, possibilitando o acesso do paciente ao diagnóstico definitivo e proposta terapêutica apropriada.

Palavras-chave: Meduloblastoma; Meduloblastoma Anaplásico; Tumor de Sistema Nervoso.

\footnotetext{
${ }^{1}$ Acadêmicos da Faculdade de Medicina Estácio. Juazeiro do Norte, CE;

${ }^{2}$ Acadêmica na Faculdade de Medicina (FAMED) da Universidade Federal do Cariri (UFCA);

${ }^{3}$ Mestrado em Educação Física pela Universidade Federal de Santa Catarina, Brasil. Docente do Centro Universitário Leão Sampaio UNILEÃO;

${ }^{4}$ Docente na Faculdade de Medicina (FAMED) da Universidade Federal do Cariri (UFCA). joatonia@yahoo.com.br
} 